\title{
Recurrent ipsilateral ectopic pregnancy after partial salpingectomy: case-report
}

\author{
Tanjona Andriamanetsiarivo Ratsiatosika ${ }^{1}$, Romuald Randriamahavonjy ${ }^{2}$, \\ Baco Abdallah Abasse ${ }^{1 *}$, Mahefarisoa Fnat ${ }^{1}$, \\ Ibrahim Housni ${ }^{1}$, Rakotovao Hery Andrianampanalinarivo ${ }^{3}$
}

\author{
${ }^{1}$ Public Health Department, Faculty of Medicine, Antananarivo, Madagascar \\ ${ }^{2}$ Department of Gynecology-Obstetrics, Soavinandriana Hospital Center, Antananarivo, Madagascar \\ ${ }^{3}$ Department of Gynecology-Obstetrics, Faculty of Medicine, Antananarivo, Madagascar
}

Received: 15 May 2018

Accepted: 05 June 2018

\author{
*Correspondence: \\ Dr. Baco Abdallah Abasse, \\ E-mail: abassebacoabadallah.doc@gmail.com
}

Copyright: (C) the author(s), publisher and licensee Medip Academy. This is an open-access article distributed under the terms of the Creative Commons Attribution Non-Commercial License, which permits unrestricted non-commercial use, distribution, and reproduction in any medium, provided the original work is properly cited.

\begin{abstract}
Ectopic pregnancy is a life-threatening condition occurring in 1-2\% of all pregnancies. The most common site of implantation for an ectopic pregnancy is the fallopian tube. Authors report a case of recurrent ipsilateral ectopic pregnancy following right partial salpingectomy of a 29-Year-Old woman that led to tubal rupture. The pregnancy was conceived spontaneously. Diagnostic of ruptured ectopic pregnancy was done after clinical and ultrasonography examination. The presence of a massive hemoperitoneum with a positive pregnancy urinary test that lead us to the diagnosis of ectopic pregnancy. She underwent a laparotomy for a suspicion of ruptured ectopic pregnancy. The ectopic pregnancy was identified in the left remnant fallopian tube. Partial salpingectomy, removal of tubal stump, and resection of the uterine cornua, was performed. The postoperative recovery was uneventful. She has stayed for five days at the Hospital. All patients, even though they have already received a definitive contraception by tubal section and ligature or unilateral or by bilateral salpingectomy for any reason, must seek an ectopic pregnancy in case of pelvic pain, vaginal bleeding and/ or amenorrhea. Authors propose to carry a total salpingectomy after a chosen surgical treatment.
\end{abstract}

Keywords: Ectopic pregnancy, Laparotomy, Salpingectomy, Tubal pregnancy

\section{INTRODUCTION}

Ectopic pregnancy is one of the main causes of the death of a woman during childbearing cycle. Three-quarters of maternal deaths occurred in quarterly woman's pregnancy is secondary and 9 out of $13 \%$ of them are related to ectopic pregnancy complications. ${ }^{1}$ It troubled 1 to $2 \%$ of pregnancies cycles. ${ }^{2}$ The case can be medically treated, by methotrexate injection or salpingectomy surgical intervention or even by salpingectomy. The process can be done by laparoscopic or laparotomy. Salpingectomy is often performed if the contralateral fallopian tube is healthy. ${ }^{3}$ The risk of recurrence varies from $18 \%$ to $26 \%$ depending on the type of treatment. ${ }^{4}$ Authors hereby report a case of tubal pregnancy which recurred after ipsilateral salpingectomy. Some cases have been reported in the literature, but this form of ectopic pregnancy remains rare.

\section{CASE REPORT}

It was about a 29-Year-Old woman, rushing to the emergency department of the University teaching 
Hospital of Gynecology and Obstetrics of Befelatanana for acute pelvic pain after six weeks of amenorrhea.

Her story was traced the day before her admission by a severe pelvic pain, of a left lateral colic type that is scored 8 out of 10 in the visual analog scale for pain, worsening by her motivation to walk until she got to the nearby doctor who prescribed her for an antalgic level I. Nothing had improved. The pain became widespread throughout the abdomen.

Her antecedents were marked by a laparotomy for left ruptured ectopic pregnancy in 2012 and three vaginal deliveries. While admitted, she was stable in hemodynamic with a blood pressure of $110 / 70 \mathrm{mmHg}$, a heartbeat rate of 96 beats per minute and a respiratory rate of 30 cycles per minute. The examination found a severe paleness, a sensitive cicatricle abdomen; urine pregnancy test was performed, proving positive. The diagnosis of ruptured ectopic pregnancy was evoked and confirmed by the pelvic echography through a demonstrating an empty uterus with a massive haemoperitoneum. The quantitative determination of plasma hCG was not available in emergency.

An urgent laparotomy was decided. It revealed a massive haemoperitoneum about $1300 \mathrm{cc}$ of a clotting blood fluid and a left ruptured tubal pregnancy developing on the rest of the partial salpingectomy (Figure 1). The ipsilateral ovary had a gestational corpus luteum. The contralateral uterine was macroscopically healthy. Salpingectomy of the left tube was performed without any particular incident (Figure 2).

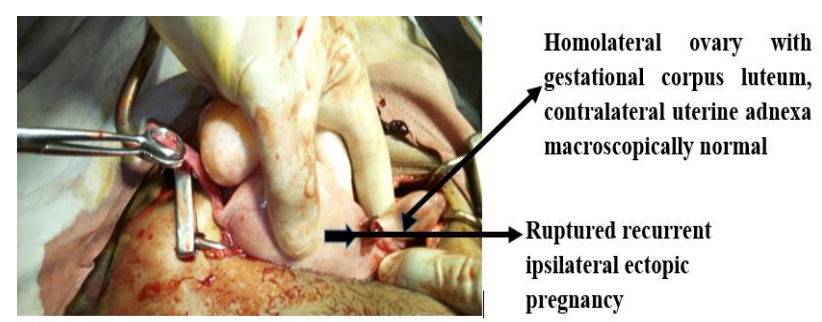

Figure 1: Left ruptured cornual ectopic pregnancy after partial salpingectomy.

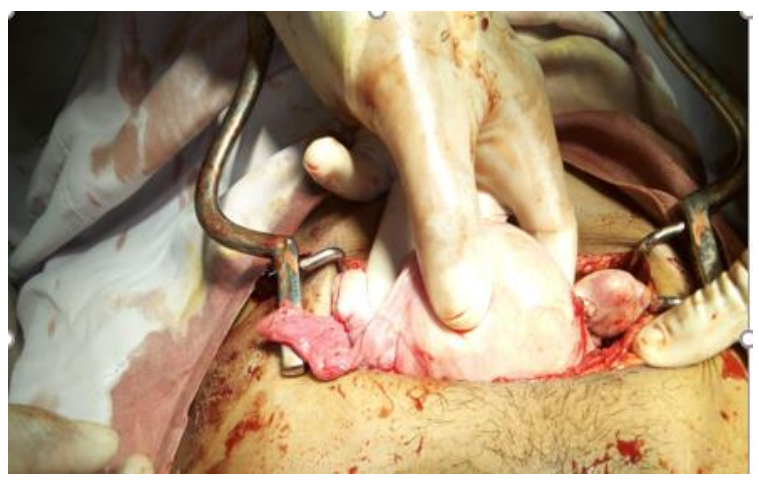

The postoperative recovery was uneventful. She has stayed for five days at the Hospital.

\section{DISCUSSION}

Recurrence of a tubal ectopic pregnancy due to ipsilateral salpingectomy is rare. Present research on MEDLINE allowed us to find similar case; about twenty cases have been reported.

Regarding Pathophysiologic, hypothesis has been advanced. One of them evokes the persistence of a receptive fallopian tube connecting the peritoneal cavity to the endometrium. The latter allows either the passage of spermatozoids that will fertilize in the oocyte and subsequently set in the fallopian tube. Or it allows the passage of an egg captured by the healthy fallopian tube and as a result migrating into the blocked fallopian tube. The second hypothesis is transperitoneal migration of a fertilized egg. The sperm go through the healthy fallopian tube and fertilizes the oocyte at the Douglas' cul-de-sac. The egg thus fertilized is captured by the fallopian pathologic and can develop as an ectopic pregnancy. ${ }^{5,6}$ This second hypothesis could explain the very rare frequency of this clinical form (Figure 3 ). ${ }^{7}$

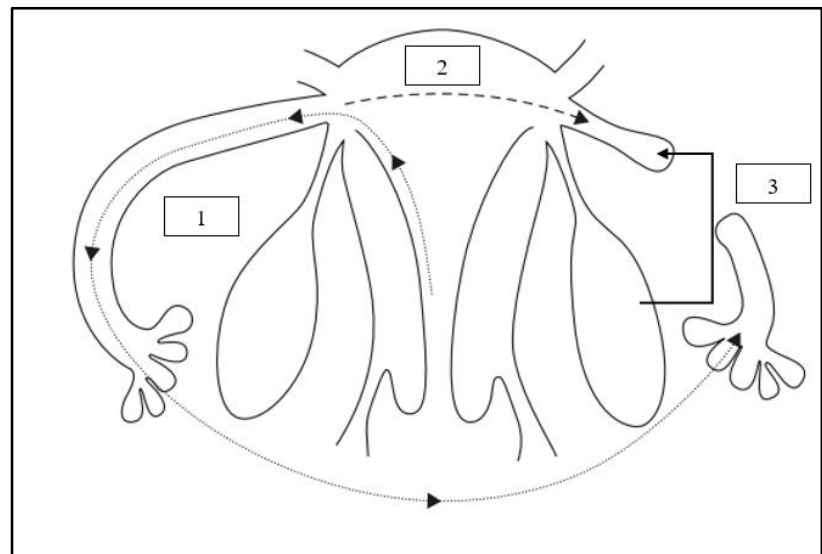

1: Trans peritoneal migration ${ }^{8} ; 2$ : Permeable tubal lumen with migration of the fertilized egg from the uterine cavity to the remnant fallopian tube ${ }^{8} ; 3$ : Oocyte uptake followed by fertilization and implantation in the fallopian tube after ipsilateral salpingectomy

Figure 3: Physiopathology of an ipsilateral ectopic pregnancy following a partial salpingectomy.

The diagnosis is based on the triad amenorrhea-pelvic pain-metrorrhagia. Echography does not allow the topography of the ectopic pregnancy to be seen most often. hCG monitoring associated with the indirect sign of ectopic pregnancy help to find the diagnostic ${ }^{9-11}$.

In present case, it is the presence of a massive hemoperitoneum with a positive pregnancy urinary test that lead us to the diagnosis of ectopic pregnancy.

Figure 2: Total left salpingectomy. 
All cases of ipsilateral recurrence develop on a partial salpingectomy. ${ }^{12}$ Authors propose more radical care treatment for the surgical treatment of ectopic pregnancies if the contralateral fallopian tube is healthy. Total salpingectomy should be performed whenever surgical treatment is indicated. Indeed, the rest of the tube may be complicated later by hydrosalpinx or implantation of the egg during medical assistance procreation. ${ }^{13}$

\section{CONCLUSION}

All patients, even though they have already received a definitive contraception by tubal section and ligature or unilateral or by bilateral salpingectomy for any reason, must seek an ectopic pregnancy in case of pelvic pain, vaginal bleeding and/ or amenorrhea.

Funding: No funding sources

Conflict of interest: None declared

Ethical approval: Not required

\section{REFERENCES}

1. Farquhar CM. Ectopic pregnancy. Lancet. 2005;366:583.

2. Barnhart K. Ectopic pregnancy. N Engl J Med. 2009;361:379-87.

3. Teresa C, Longoria MD, Megan L, Stephenson MD, Vinita J, Speir MD. Live Unilateral Twin Ectopic pregnancy in a fallopian tube remnant after previous ipsilateral salpingectomy. J Clinical Ultrasound. 2014;42(3):169-71.

4. De Bennetot M, Rabischong B, Aublet-Cuvelier B, Belard F, Fernandez H, Bouyer J et al. Facteurs de risque de récidive des grossesses extra-utérines. J Gynecol Obstet Biol Reprod. 2012;45:55-61.

5. Fruscella L, Danti M, Toti R. Extrauterine pregnancy in residual tube stump in a patient already treated with partial salpingectomy for right ampullar pregnancy. Report of a clinical case. Minerva Ginecol. 1994;46:695-7.

6. Takeda A, Manabe S, Mitsui T, Nakamura H. Spontaneous ectopic pregnancy occurring in the isthmic portion of the remnant tube after ipsilateral adnexectomy: report of two cases. J Obstet Gynaecol Res. 2006;32:190-4.

7. Cartwright PS, Entman SS. Repeat ipsilateral tubal pregnancy following partial salpingectomy: a case report. Fertil Steril. 1984;42:647-8.

8. Chou SY, Ming IH, Pui-ki C, Chiang HK, Su HW, Hsu CS. Recurrent ipsilateral ectopic pregnancy after partial salpingectomy. Taiwan J Obstet Gynecol. 2009;48(4):420-2.

9. Zuzarte R, Khong CC. Recurrent ectopic pregnancy following ipsilateral partial salpingectomy Singapore Med J. 2005;46(9):476.

10. Milingos DS, Black M, Bain C. Three Surgically Managed Ipsilateral Spontaneous Ectopic Pregnancies. Am College Obstetr Gynecol. 2008;112:458-9.

11. Chou SY, Ming IH, Pui-ki C, Chiang HK, Su HW, Hsu CS. Recurrent ipsilateral ectopic pregnancy after partial salpingectomy. Taiwan J Obstet Gynecol. 2009; 48(4):420-2.

12. Abraham C, Seethappan V. Spontaneous live recurrent ectopic pregnancy after ipsilateral partial salpingectomy leading to tubal rupture. Int J Surg Case Reports. 2015;7:75-8.

13. Tan TL, Elashry A, Tischner I, Jolaoso A. Lightning does strike twice: Recurrent ipsilateral tubal pregnancy following partial salpingectomy for ectopic pregnancy. 2007;27:534-5.

Cite this article as: Ratsiatosika TA, Abasse BA, Fnat M, Housni I, Randriamahavonjy R,

Andrianampanalinarivo RH. Recurrent ipsilateral ectopic pregnancy after partial salpingectomy: casereport. Int J Reprod Contracept Obstet Gynecol 2018;7:2930-2. 